\title{
Aos Autores da Narrativa da Contemporaneidade
}

To the contemporary narrative authors

Cremilda Celeste de Araújo Medina - ECA-USP | São Paulo | São Paulo | Brasil | Email: medinase@usp.br | https://orcid.org/0000-0002-3985-0884

Resumo: Em conferência proferida aos alunos de Jornalismo da Universidade de Sorocaba e demais membros da comunidade universitária, Cremilda Celeste de Araújo Medina recupera sua trajetória forjada entre o laboratório da arte de tecer o presente e a academia. A experiência rememorada da referência para os pesquisadores em comunicação permite observar a elaboração epistemológica que orienta sua abordagem como comunicadora e pesquisadora da área. 0 registro da fala foi recuperado e revisado pela autora.

Palavras-chave: Jornalismo. Arte de tecer o presente. Atravessagem. Diálogo social. Afeto.

Abstract: In a conference given to Journalism students at the University of Sorocaba and other members of the university community, Cremilda Celeste de Araújo Medina recovers her forged trajectory between the laboratory of the art of weaving the present and the academy. The recollected experience of reference for communication researchers allows us to observe the epistemological elaboration that guides her approach as a communicator and researcher in the area. The speech record was retrieved and reviewed by the author.

Keywords: Journalism. The art of weaving the present. Crossing. Social dialogue. Affection.

- Recebido em: 28 out. 2019 • Aprovado em: 01 nov. $2019 \bullet$ e-ISSN: 2177-5788

DOI: https://doi.org/10.22484/2177-5788.2019v45n2p463-475

Copyright @ 2019. Conteúdo de acesso aberto, distribuído sob os termos da Licença Internacional da CreativeCommons - CC BY-NC-SA - Atribuição Não Comercial (https://br.creativecommons.org/licencas/) - Permite distribuição e reprodução, desde que atribuam os devido créditos à publicação, ao autor(es) e que licenciem as novas criações sob termos idênticos. 


\section{Introdução}

O presente artigo originou-se da conferência proferida pela professora Cremilda Celeste de Araújo Medina em 28 de maio de 2019, durante a abertura da $2^{\circ}$ Mostra de Pesquisa em Jornalismo, organizada pela coordenação do curso de graduação de Jornalismo da Universidade de Sorocaba. Assim, o texto guarda nuances típicos de uma redação elaborada com a finalidade de uma exposição oral, o que confere um aspecto poético em alguns momentos e o uso da primeira pessoa que serão mantidos.

\section{A Conferência pela Conferencista}

Permitam, prezados leitores acadêmicos, mas vou iniciar a Atravessagem de etapas de pesquisa com um texto do primeiro semestre de 2019, escrito para uma oficina de "Narrativas da Contemporaneidade" proposta a alunos da terceira idade.

\section{Pombas, Sabiás, Maritacas e o Condomínio}

Escutai, meus companheiros ancestrais: eu, na condição de pomba mais velha, matriarca do bando, estou revoltada. Não é que nos tiraram aquela comidinha deliciosa da varanda do primeiro andar. Voamos todos os dias da Praça Buenos Aires em direção ao prédio naquele corredor, a favor do vento. Na Praça, os restos de alimento andam escassos, então descobrimos aquele manjar que a velha senhora nos oferece. Foi só aparecerem os pratinhos de sementes, de ração da melhor qualidade e de pedacinhos de mamão, que a passarada avisou. Não só meus parentes, pombos, pombas e pombinhos, como sabiás e maritacas correram em direção ao banquete. Sim, verdadeiro banquete que ontem desapareceu. Não é justo.

Meu Deus, como vou passar os fins de tarde, com chuva ou sol, sem o canto dos meus passarinhos? A alegria de servir a mesa pra eles. A mesa, modo de dizer, a varanda. Fico encantada com o voo em direção ao meu 
apartamento, talvez tenha sido a melhor ideia para a terrível solidão que sofro depois da morte do meu marido. Costumávamos sentar na varanda e conversar, ele com assunto sem fim, sua voz que se parece - quer dizer, parecia - com canto de sabiá. Eram fins de tarde, principalmente no verão, em que o papo rolava, às vezes competindo com os pássaros da Praça Buenos Aires. Hoje, que o Henrique se foi, que Deus o tenha, só os sons à distância no jardim. Mas, há um mês, mistérios da insônia, acordei com o plano arquitetado: vou chamar a companhia dos passarinhos pra minha varanda... Minha cumplicidade com os bichinhos, não contava com isso, foi interrompida à força com a agressiva oposição da vizinha do quarto andar.

Qué que deu na velha do primeiro andar? Onde já se viu botar comida para pássaros na varanda. Um horror. Pombas, sabiás, maritacas e sei lá quem mais desandaram a comer e a defecar na capota do meu carro. Pois é: este prédio não tem garagem pra todo mundo, parece que na década de 1940, quando foi construído, nem se pensava em carro individual. Acontece que em casa temos dois carros, aí alugamos a garagem, numa das raras vagas do prédio. O segundo carro não cabe por inteiro, fica com a traseira pra fora. O condomínio me cobra outro aluguel. Que querem? Trabalhamos e merecemos ter dois carros, não me venham com luxos. E o que não cabe dentro fica bem de baixo da varanda da dona Mirtes. Então foi aquele Deus nos acuda de cocô no meu carro, além da gritaria das maritacas que chega até minha varanda nas horas mais impróprias.

Como síndico do prédio tive que encarar uma situação surrealista. Em toda a minha administração nunca imaginei resolver um problema de fezes de pombas no teto de um automóvel. Como ser juiz de defecações de pássaros? De um lado, a velha senhora viúva, que nunca fez mal a ninguém, arrumou essa companhia e se diverte com o concerto da passarada na varanda do primeiro andar; de outro lado, a indignada vizinha do quarto andar a buzinar no meu ouvido com a capota do carro toda suja. Queria, primeiro, que o funcionário da limpeza resolvesse o problema todas as manhãs. Ó minha senhora, não temos faxineiro particular para o seu carro. 
Ora, tenha paciência, é preciso arrumar outra solução. Quem sabe a senhora cobre com uma lona o carro e assim só fica a lona pra limpar de vez em quando.

Nem pensar, essa solução é absurda. Eu que vou limpar a lona? Mande então a velha dos pássaros resolver de uma vez a questão. Já mandei para a imobiliária uma reclamação e nem responderam. Estou a ponto de chamar a televisão pra filmar o meu carro todo, perdão da palavra, mas é isso mesmo, todo cagado. O condomínio tem que tomar uma atitude.

Senhor síndico, essa minha vizinha do quarto andar não tem jeito. Sou uma velha paciente, compreensiva. Veja bem, a garagem não é pra dois carros e se ela tem um segundo automóvel com o traseiro pra fora, que se vire. Meus passarinhos são meus amigos, até converso com eles. Dou, sim, muita comidinha e mesmo que diminuísse as porções dos pratinhos, ainda assim não poderia impedir que façam cocô na área. Se não estivesse o maldito carro embaixo da minha varanda...

Não tem mais discussão nem com a velha nem com o síndico. Vou entrar com uma ação na justiça. Uma última proposta: o condomínio manda fazer um toldo de alumínio ou de lona, não me interessa, e põe embaixo da varanda do primeiro andar, em cima do meu carro. Se não tiver reserva de fundos no condomínio, ela que pague.

Esta senhora é maluca. Como vou fazer uma obra por causa do cocô dos pássaros? Tenho que conversar com minha amiga do primeiro andar, a ver se a dona Mirtes se convence de tirar o restaurante da varanda. Só assim para não ter que instalar uma privada para os bichos... Hoje estou novamente de luto. Primeiro foi o Henrique, agora meus passarinhos. Se não tirasse a comidinha da varanda, este condomínio virava uma guerra. Ei, gentil passarada. Temos de voar pra outra freguesia. Apesar de minha autoridade como líder, não posso fazer nada por vocês, meus companheiros: acabaram com os alimentos do espírito e da pança na varanda de vossa e minha amiga. Era bom, mas se acabou. Coisas da vida.

Cremilda Medina (moradora do Condomínio). (São Paulo, 5 jun. 2019, texto baseado em fatos reais e complementos de ficção que a realidade inspira) 
Por que este texto de abertura? Porque, no atual momento de pesquisa e reflexão o principal desafio é experimentar na prática e estudar na teoria o plurálogo de sentidos nas vozes, comportamentos e circunstâncias humanas. Ao partir da dialogia social e da responsabilidade do mediador-autor nas narrativas da contemporaneidade (no centro das mesmas, o Jornalismo), tem sido desafiante descentralizar o Eu-Técnico para o Nós-Estético da ética da relação solidária, tema tão caro à autora Mara Rovida (2015) em seu livro "Jornalismo em trânsito, o diálogo social solidário no espaço urbano".

Ao ser convidada para uma intervenção acadêmica na UNISO, em 28 de maio de 2019, quando foram expostos os trabalhos de conclusão do curso de Jornalismo, propus aos jovens formandos uma síntese da retrospectiva dos estudos que venho desenvolvendo em grupo ou por iniciativa individual até o presente momento.

A atravessagem se inicia na formação universitária (1960-1964) dos cursos de Jornalismo e de Letras na Universidade Federal do Rio Grande do Sul. Na profissionalização como jornalista, em 1962, o ofício inerente ao repórter, três habilidades passam a ser cultivadas: a escuta curiosa, a captação da síntese de depoimentos, a observação em campo, a escrita linguística e a escrita de códigos visuais (diagramação e fotografia). Nasce como definição metodológica o interesse pela leitura cultural, enriquecida pela literatura, o cinema, o teatro, a música. O trânsito ao atravessar as circunstâncias e ir ao encontro dos protagonistas sociais se reveste de responsabilidade ética, segundo a consciência formada em disciplinas como História, Sociologia, Antropologia, Letras, Geografia Humana e outros fundamentos humanísticos tão presentes na universidade pública dos primeiros anos da década de 1960.

Gradualmente, a noção de captar os significados plurais e em conflito da cultura contemporânea, expressa nos comportamentos e na codificação (linguística e demais códigos), se tornou uma inquietude prática e teórica para a leitura cultural do jornalista. O que, em princípio, seria um linear 
processo de pesquisa e atividade jornalística, não fossem os percalços da história.

\section{Ruptura de Utopias - 31 de março de 1964 e a Noite da Formatura em Jornalismo}

Inicia-se, nesta data, a consciência dilacerada da resistência cultural e o enfrentamento dos medos da repressão. E em 1967, convidada para ser assistente de catedrático na disciplina técnica cujo laboratório era o Jornal Escola, acompanharia em um dos focos de acirramento da ditatura militar, a universidade, o ano de inflexão persecutória - 1968. Com a formação pedagógica do curso de Letras, os estudos de humanidades e o convívio com as artes, torna-se inconsistente a simples transmissão técnica ao desenvolver o jornal-laboratório na Faculdade de Filosofia, Ciências e Letras. Mais ainda quando se criam as faculdades de comunicação social a partir da pioneira Escola de Comunicações e Artes da Universidade de São Paulo (1966). Também no Sul, acontece a autonomia dos cursos de Jornalismo, Publicidade e Biblioteconomia e participo das novas instalações da atual FABICO - Faculdade de Biblioteconomia e Comunicação da Universidade Federal do Rio Grande do Sul.

Fermenta, na esfera internacional, a ebulição da pesquisa nas ciências da comunicação, em que teoria e prática aparecem conjugadas. No final dos anos 1960, comenta-se na universidade brasileira a nova política de pósgraduações. Chega a Porto Alegre a notícia de que a ECA/USP iria criar o primeiro curso da América Latina. Para além das circunstâncias políticas desfavoráveis, a motivação por aprofundar conhecimentos me faz viajar a São Paulo em julho de 1970 com dois objetivos: participar da Primeira Bienal do Livro (trabalhava então na Editora Globo de Porto Alegre) e aproveitar a oportunidade para uma visita à Escola de Comunicações e Artes da Universidade de São Paulo. José Marques de Melo (1943-2018), o então chefe do departamento, me recebe com afeto e me cativa. Voltaria ao Sul, tomada por uma decisão em curso. 


\section{As Sementes da Pesquisa estão Lançadas (1971-1975)}

Vim do Rio Grande do Sul, em dezembro de 1970, com o projeto de mestrado esboçado: "A estrutura da mensagem jornalística", que se realizaria na dissertação do primeiro mestrado da América Latina em Ciências da Comunicação em 1975 e seria publicado em 1978, sob o título "Notícia, um produto à venda, jornalismo na sociedade urbana e industrial". Antes, porém, da defesa do mestrado, a mentalidade da pesquisa, inerente ao DNA da USP, resultará, em 1972-73, no primeiro livro, publicado artesanalmente na universidade, "A arte de tecer o presente", assinado com o colega de docência, Paulo Roberto Leandro (1973). Mas em 1975, ocorre uma nova ruptura quando três dos professores, o chefe do departamento, Walter Sampaio (1931-2002), Paulo Roberto Leandro e eu saímos da USP em solidariedade à cassação do professor que implantara o curso de Editoração, Sinval Medina.

No entanto, o período de 1971 a 1975 foi decisivo ao fertilizar as sementes da pesquisa e da união indissolúvel entre teoria e prática. As marcas ficaram registradas na graduação de Jornalismo, na profissão e nos desafios da responsabilidade social da mediação jornalística em um trânsito intenso no Brasil e na América hispânica (via CIESPAL, o Centro Internacional de Estudos Superiores de Periodismo para a América Latina).

Extraio deste período palavras-chave que me orientarão nos estudos posteriores ao mestrado: a arte de tecer o presente, complexidade e pluralidade da produção simbólica na comunicação social, autoria e responsabilidade na mediação jornalística.

\section{Convívio Cotidiano com a Arte (1975-1985)}

Ao sair da Universidade de São Paulo, em plena ditadura militar e assumir, no jornal "O Estado de S. Paulo", a Editoria de Artes e Cultura, pude conjugar minhas duas formações humanísticas e cruzar as técnicas gramaticalizadas do Jornalismo, com a expressão inovadora e solidária dos artistas. Além do cotidiano gratificante (pois os artistas, escritores na 
primeira linha, formavam um dos movimentos sociais mais vigorosos no confronto com a censura institucional e os desatinos da repressão), iniciei um ciclo de viagens às literaturas da língua portuguesa - Portugal, Brasil e África - que me proporcionou lançar sondas (de repórter) na atravessagem simbólica entre povo e personagem, palavra-chave, do gesto da arte e da leitura cultural na interpretação da reportagem.

Diria na introdução do meu livro sobre os escritores brasileiros:

A história da literatura é, de certa forma, a história do apossamento da terra, da identidade de um povo, da fixação dos verdadeiros marcos, que são complexos, interpenetrando o particular e o geral. Os escritores como os artistas de todas as demais expressões, vêm tomando posse do continente descoberto no século XVI. Não uma posse predatória como tantas outras, mas aquela que se define no autoconhecimento, na compreensão das próprias forças, das grandezas e limitações. Se pudesse, o artista agarrava o destino traçado no comportamento de sua gente e o transpunha ao paraíso (MEDINA, 1985, p. 13-14).

Daí a nova chave da oficina epistemológica com acento na dialogia social: a fruição e a inspiração do gesto da arte.

\section{A Volta à USP e as Completudes Ensino-Pesquisa-Comunicação Social}

Em 1986, o doutorado e o retorno à pesquisa, docência e comunicação social reataram os laços de ciência e sociedade. Já em 1987, se iniciava o laboratório de dialogia social, que rege a proposta da série "São Paulo de Perfil", hoje 26 livros publicados e um inédito. Na experiência laboratorial, as palavras-chave, respeito ao Outro, diálogo possível, observação-experiência, pesquisa identitária, complexidade e pluralidade de forças simbólicas, mediação autoral, estilística inspirada em campo, no estar afeto a.

Os 500 autores que marcam com suas reportagens a coleção dedicada a três famílias temáticas - migrações para São Paulo, espaços sócio culturais ou desafios da cidadania da grande metrópole - deixam registrada a demonstração prática de uma escrita solidária, de técnica rigorosa e de estética inovadora. De tal forma que a coleção tem sido campo de reflexão 
em mestrados, doutorados ou ensaios. Este ano, 2019, os alunos do Programa da Terceira Idade da USP, debateram na oficina que Ihes ofereço - "Narrativas da Contemporaneidade" - os livros da série "São Paulo de Perfil" e dessa imersão saíram inspirações para a publicação de autoria do grupo que sairá no próximo ano. Os idosos atualizaram a própria memória e as cenas vivas do mesmo território; ao mesmo tempo, se espantam, hoje, com a sensibilidade e competência dos jovens repórteres dos anos 1980 à primeira década deste século. As histórias humanas que eles narram elegem como foco o sutil mergulho nas tramas anônimas do cotidiano (outro eixo fundamental do projeto).

Inicia-se também, em 1987, a docência e a orientação de mestres e doutores na pós-graduação: as teorias latino-americanas de comunicação social estão atravessadas pelas mesmas noções-chave. Nunca estabeleci fronteira estrita de graduação, pós-graduação, pós-doutorado ou programas voltados para a terceira idade. O laboratório epistemológico abraça todas as faixas etárias. Há mesmo resultados que aglutinam alunos das diferentes faixas acadêmicas: livros da série antes citada reúnem autores da graduação, da pós, da terceira idade, bem como colaboradores especializados no tema. Só essa história da interação acadêmica mereceria um ensaio à parte. Casos como as experiências sobre a periferia de São Paulo - "À margem do Ipiranga" (v. 8, 1991); "Tietê, mãe das águas" (v. 17, 1995); "Ó Freguesia, quantas histórias" (v. 23, 2000) - são exemplares. O sociólogo da USP Lúcio Kowarick, ao ser convidado para colaborar com um artigo sobre o tema, ele próprio solicitou, antes de escrever, a leitura das reportagens para sentir na narrativa das cenas vivas e, da voz dos sujeitos protagonistas, captar interrogantes no seu ensaio "Periferias e subcidadania" (KOWARICK, 1991). O sociólogo reconheceu a força da pesquisa de campo na reportagem autoral. 


\section{1990, Marco da Inter e Transdisciplinaridade}

O "Primeiro Seminário Inter e Transdisciplinar: A Crise de Paradigmas" (MEDINA, 1991) assinala o lançamento de uma fase que permanece até hoje, em que a atravessagem colhe teórica e praticamente as encruzilhadas dos saberes científicos, dos saberes cotidianos e das linguagens míticas. Na dialogia ciência-sociedade, sociedade-ciência, o mediador-autor não é um mero transmissor nem tampouco um técnico divulgador; nas narrativas da contemporaneidade cruzam-se tempos (seta do tempo, ciclo do tempo como nos indica Stephen Gold (1991)), espaços múltiplos, inclusive os do imaginário; complexidade de miscigenações culturais; intercausalidades do acontecimento; direito à transcendência do real concreto; o coletivo na produção de sentidos e muitas outras noções que a prática ou a reflexão transdisciplinar acrescenta à oficina do jornalista. Eis um convite ao permanente aprofundamento nos impasses e provisórias soluções da ação humana (da medicina à cozinha doméstica, da estatística à antropologia, da história à comunicação social, da física à matemática, da biologia à educação, da arte às neurociências).

Os encontros e as reflexões dos autores vizinhos ou artificialmente distanciados nas hierarquias acadêmicas vêm desaguar no "Projeto Plural" (nome fantasia que assumiu a série de livros "Novo Pacto da Ciência"). Aprendemos muito com as desconstruções paradigmáticas que frequentam as mentalidades no saber plural. Um exemplo eloquente é o das neurociências, e a fértil obra publicada de António Damásio (2018) que, dos estudos pragmáticos perante as moléstias do cérebro, vem extraindo hipóteses teóricas que nos desbravam.

Temos um espaço de ação desafiante em meio a toda a ebulição contemporânea: a reportagem e o ato presencial em que se realiza. Sim, em tempos de conexões à distância, persiste, no meu entendimento e experiência, a incomparável oportunidade de interação social criadora do ato presencial. Não se desvaloriza toda a bagagem (espaços/tempos) da internet, o quanto nos ajuda na agilidade das travessias. Mas a 
atravessagem humana não prescinde dos cinco sentidos em presença, mobilizando a compreensão do Outro em sua ação e sutilezas. A intuição do ritmo narrativo e da criação de narradores emerge do ato presencial, dificilmente surgirá no ato digital, pelo menos enquanto o contato nesse meio não contar com toque corporal - um simples aperto de mão ou abraço -, a conjugação de preciosos sentidos como paladar e olfato, uma visão despoluída de prejulgamentos ou a percepção intimista articulada com a escuta perturbadora do plurálogo.

Por isso, ao encontrar os formandos da Universidade de Sorocaba (UNISO) naquela noite de festa, só podia acenar com minha aposta.

Muita sorte e encantamento aOs REPÓRTERES DO SÉCULO XXI.

\section{Referências}

DAMÁSIO, António. A estranha ordem das coisas. São Paulo: Cia. das Letras, 2018.

GOLD, Stephen Jay. Seta do tempo, ciclo do tempo. São Paulo: Cia. das Letras, 1991.

KOWARICK, Lúcio. Periferias e subcidadania. In: MEDINA, Cremilda (org.). À margem do Ipiranga. São Paulo: CJE/ECA/USP,1991. v. 8

LEANDRO, Paulo Roberto; MEDINA, Cremilda de Araújo. A arte de tecer o presente. São Paulo: Media, 1973.

MEDINA, Cremilda (org.). A crise de paradigmas: primeiro seminário transdisciplinar. São Paulo: ECA, 1991. (Novo Pacto da Ciência, 1).

MEDINA, Cremilda (org.). Ó Freguesia, quantas histórias. São Paulo: ECA/USP, 2000. (São Paulo de Perfil, 23).

MEDINA, Cremilda (org.). Tietê, mãe das águas. São Paulo: CJE/ECA/USP, 1995. (São Paulo de Perfil, 17).

MEDINA, Cremilda de Araújo. A posse da terra, escritor brasileiro hoje. Lisboa: Imprensa Nacional-Casa da Moeda, 1985.

ROVIDA, Mara Ferreira. Jornalismo em trânsito, o diálogo social solidário no espaço urbano. São Carlos: EdUFSCar, 2015. 